\title{
Effects of calcium carbonate on hydro-mechanical properties of bentonite
}

\author{
Xian-Lei $\mathrm{Fu}^{1,2,3}$, Ai-Fang Qin ${ }^{1 *}$, Wei-Fang $\mathrm{Xu}^{1}$ and Liang-Hua Jiang ${ }^{1}$ \\ ${ }^{1}$ Department of Civil Engineering, Shanghai University, Shanghai 200444, China \\ ${ }^{2}$ B-Z Geotechnical Co. Ltd., Nanjing, Jiangsu 210096, China \\ ${ }^{3}$ Institute of Geotechnical Engineering, Southeast University, Nanjing, Jiangsu 210096, China
}

\begin{abstract}
To simulate characteristic changes of the bentonite mixing with $\mathrm{CaCO}_{3}$ crystals that precipitate from groundwater around the high-level radioactive waste repositories, different amounts of $\mathrm{CaCO}_{3}$ powders were mixed in the bentonite. In this study, four series of bentonite/ $\mathrm{CaCO}_{3}$ mixtures were prepared with different contents of $\mathrm{CaCO}_{3}$ powders. A series of swelling, compression and direct shear tests were conducted on the bentonite $/ \mathrm{CaCO}_{3}$ samples using deionized water. Terzaghi consolidation theory was adopted to compute the hydraulic conductivity of bentonite $/ \mathrm{CaCO}_{3}$ mixtures. The results demonstrated that the final swelling strain decreased with increasing vertical stress and the content of $\mathrm{CaCO}_{3}$ powders. The compression index decreased slightly with increasing $\mathrm{CaCO}_{3}$ content. It was found that as the $\mathrm{CaCO}_{3}$ content increased, the hydraulic conductivity of bentonite $/ \mathrm{CaCO}_{3}$ mixtures decreased. There was a peak point in the shear strength of unsaturated samples with the differences of the $\mathrm{CaCO}_{3}$ content. The cohesion of unsaturated samples increased first and then decreased, but saturated samples presented the opposite character. It could be seen from the scanning electron micrograph that the existence of $\mathrm{CaCO}_{3}$ powders filled pores of bentonite/ $\mathrm{CaCO}_{3}$ mixtures and made the structure denser.
\end{abstract}

\section{Introduction}

Deep geological disposal has been widely adopted by many countries as a safe and effective treatment to deal with the long-term radioactive waste. For disposal of the high-level radioactive waste (HLW), the bentonite or bentonite-based materials are generally used as buffer materials due to their favorable properties such as high swelling, high radionuclide retardation and low permeability [1-5].

For the security of repository, the bentonite materials have been widely investigated for their mechanical properties [6-10] and hydraulic behavior [11-14]. Performance of the bentonite in the repository is normally affected by high temperature [15-18], chemical effects [20-23] and gas [24-29], and even the coupling of several situations. Thus, it is necessary to study properties of the bentonite under different surroundings.

With the closure of the repository, groundwater intrudes into the bentonite continuously. This means that many ions which are soluble in the groundwater can be bought into the bentonite, including the lower hydration energy of the exchangeable monovalent cation such as $\mathrm{Na}^{+}$and divalent cation $\mathrm{Ca}^{2+}$ [30]. Meanwhile the surrounding environment also has many anions such as bicarbonate ions and carbonate ions. Guo et al. [31-32] investigated the groundwater composition in Beishan (Gansu province of China) and Yumeng Su (Xinjiang province of China), and analyzed the chemical characteristics. They found that the groundwater in the researched area was mainly saline with high dissolved solids, 7.39-10.14 $\mathrm{pH}$ value, $8-17^{\circ} \mathrm{C}$ temperature, $0.7-19 \mathrm{~g} / \mathrm{L}$ total dissolved solids. It was concluded that the groundwater of Beishan mainly composed of sodium ions, calcium ions, sulfate ions and bicarbonate ions. Bicarbonate ions are likely to be converted to carbonate ions in alkaline conditions (Eqs. (1) and (2)) and most minerals in groundwater had reached saturation in this area. With the increase of salinity, calcium ions in the groundwater combine with carbonate ions to form precipitates.

$$
\begin{gathered}
\mathrm{HCO}_{3}+\mathrm{OH}=\mathrm{CO}_{3}^{2}+\mathrm{H}_{2} \mathrm{O} \\
\mathrm{HCO}_{3}+\mathrm{H}_{2} \mathrm{O}=\mathrm{H}_{2} \mathrm{O}+\mathrm{CO}_{2}+\mathrm{OH}
\end{gathered}
$$

In addition, the gases such as carbon dioxide, hydrogen and methane can be produced due to the microbial degradation process in the long-term operation of the deep geological repository system. carbon dioxide produced by microorganism can increase the gas pressure in the bentonite and facilitate the formation of bicarbonate ions and carbonate ions, which combine with calcium ions to form precipitates. Meanwhile, Sasaki et al. [33] reported that the microbial respiration can induce calcium carbonate in the soil.

\footnotetext{
*Corresponding author's e-mail: qinaifang@shu.edu.cn
} 
It can be seen that there are several ways of forming $\mathrm{CaCO}_{3}$ crystals. Therefore, it is extremely important to study the effect of $\mathrm{CaCO}_{3}$ crystals on properties of the bentonite. In this paper, experiments were performed on the bentonite with different calcium carbonate mixing ratios (CMR) to study its swelling, compression, and permeability properties. The study of strength characteristics is divided into saturated and unsaturated to simulate the near heat source point and near rock point in the repository respectively. Afterwards, the conclusions were verified based on the analysis of testing results.

\section{Materials and experimental methods}

\subsection{Materials and sample preparation}

The bentonite used in the experiment was taken from Qitai County, Xinjiang, which is one of the Chinese nuclear waste buffer materials. The bentonite was crushed through a $0.5 \mathrm{~mm}$ sieve before the experiment. Basic properties of the bentonite were shown in Table 1. $\mathrm{CaCO}_{3}$ powders which were white powders and composed of aragonite and calcite crystals with a density of $2.72 \mathrm{~g} / \mathrm{cm}^{3}$ were produced by Sinopharm Group (No.10005760). In order to avoid the influence of the metal ions on the bentonite properties, the deionized water was used.

Table 1. Basic properties of the bentonite.

\begin{tabular}{cc}
\hline Parameter & Value \\
\hline Specific gravity of soil grain & 2.71 \\
Liquid limit $w_{\mathrm{L}}(\%)$ & 152.3 \\
Plastic limit $w_{\mathrm{P}}(\%)$ & 52.5 \\
Ion exchange capacity & 94.65 \\
(mol/100g) & $\mathrm{Na}^{+} / 65.18$ \\
Mainly exchangeable ions & $1 / 2 \mathrm{Ca}^{2+} / 21.60$ \\
(mol/100g) & $1 / 2 \mathrm{Mg}^{2+} / 6.34$ \\
& $\mathrm{~K}^{+} / 0.52$ \\
& Montmorillonite $/ 75.9 \%$ \\
Main mineral composition & Quartz $/ 14.2 \%$ \\
& Feldspar $/ 5.9 \%$ \\
$\mathrm{Na}_{2} \mathrm{O}(\%)$ & Gypsum $/ 4.0 \%$ \\
$\mathrm{CaO}(\%)$ & 2.96 \\
& 1.2 \\
\hline
\end{tabular}

suitable volume of different samples, the quantity of mixed samples was calculated. Finally, compressed unsaturated samples were obtained by CTM8050 universal testing machine. The initial state of each sample was shown in Table 2. experiment were placed into a $105^{\circ} \mathrm{C}$ constant temperature oven to keep them completely dry firstly. 24 hours later, these specimens were removed immediately and then the different amounts of $\mathrm{CaCO}_{3}$ powders $(0 \%$, $3.125 \%, 6.25 \%$ and $12.5 \%$ ) were mixed with the bentonite samples after cooling down. The water content of the target was $15 \%$. Then these mixtures were maintained 24 hours to ensure that water in the mixed samples was evenly distributed. According to the initial overall dry density $\left(1.6 \mathrm{~g} / \mathrm{cm}^{3}\right)$ of the target and the

\subsection{Experimental method}

The whole experimental process included four tests: 1) Swelling test, 2) Oedometer test, 3) Scanning electron microscope test and 4) Shear test.

Table 2. Initial states of samples

\begin{tabular}{|c|c|c|c|c|c|c|c|}
\hline NO. & $\begin{array}{c}\text { CMR } \\
(\%)\end{array}$ & $\begin{array}{l}\text { Height } \\
(\mathrm{mm})\end{array}$ & $\begin{array}{l}\text { Diameter } \\
(\mathrm{mm})\end{array}$ & $\begin{array}{l}\text { Bentonite dry density } \\
\left(\mathrm{g} / \mathrm{cm}^{3}\right)\end{array}$ & $\begin{array}{c}\text { Swelling } \\
\text { test }\end{array}$ & $\begin{array}{c}\text { Odometer } \\
\text { test }\end{array}$ & $\begin{array}{c}\text { Direct shear } \\
\text { test }\end{array}$ \\
\hline \multirow[t]{3}{*}{1} & 0 & 10 & 61.8 & 1.6 & $\sqrt{ }$ & \multirow[t]{3}{*}{$\sqrt{ }$} & \\
\hline & 0 & 15 & 61.8 & 1.6 & $\sqrt{ }$ & & $\sqrt{ }$ \\
\hline & 0 & 15 & 50 & 1.6 & & & $\sqrt{ }$ \\
\hline \multirow[t]{3}{*}{2} & 3.125 & 10 & 61.8 & 1.55 & $\sqrt{ }$ & \multirow[t]{3}{*}{$\sqrt{ }$} & \\
\hline & 3.125 & 15 & 61.8 & 1.55 & $\sqrt{ }$ & & $\sqrt{ }$ \\
\hline & 3.125 & 15 & 50 & 1.55 & & & $\sqrt{ }$ \\
\hline \multirow[t]{3}{*}{3} & 6.25 & 10 & 61.8 & 1.5 & $\sqrt{ }$ & \multirow[t]{3}{*}{$\sqrt{ }$} & \\
\hline & 6.25 & 15 & 61.8 & 1.5 & $\sqrt{ }$ & & $\sqrt{ }$ \\
\hline & 6.25 & 15 & 50 & 1.5 & & & $\sqrt{ }$ \\
\hline \multirow[t]{3}{*}{4} & 12.5 & 10 & 61.8 & 1.4 & $\sqrt{ }$ & \multirow[t]{3}{*}{$\sqrt{ }$} & \\
\hline & 12.5 & 15 & 61.8 & 1.4 & $\sqrt{ }$ & & $\sqrt{ }$ \\
\hline & 12.5 & 15 & 50 & 1.4 & & & $\sqrt{ }$ \\
\hline
\end{tabular}


2.2.1. Swelling test. As shown in Figure 1, the compressed samples were placed in the oedometer apparatus. While the vertical prestressing of $1 \mathrm{kPa}$ was applied, the initial reading of the dial gauge was recorded. Then the target vertical stress was reached (the samples with the height of $15 \mathrm{~mm}$ were loaded to 200,400 and $800 \mathrm{kPa}$, respectively; the samples with the height of $10 \mathrm{~mm}$ were loaded to $50 \mathrm{kPa}$ ) through step loading method. The deionized water was not injected into the consolidation cell until the reading of dial indicator remained stable (the reading changed $0.01 \mathrm{~mm}$ within $1 \mathrm{~h}$ ). Finally, when the change of the reading of dial gauge was less than $0.01 \mathrm{~mm} / 24 \mathrm{~h}$, the loaded swelling test was terminated.

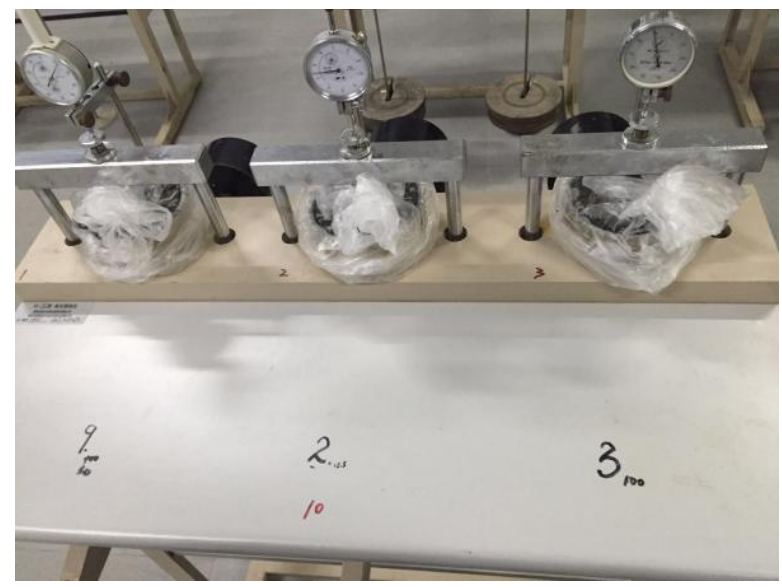

Figure 1. The oedometer apparatus.

The swelling strain was adopted to describe swelling properties of the bentonite. The swelling strain was defined as:

$$
\varepsilon=\frac{\Delta H}{H_{0}} \times 100 \%
$$

Where $\varepsilon$ is the swelling strain, $\Delta H$ is the vertical deformation $(\mathrm{mm})$ and $H_{0}$ is the initial height of samples (mm).

2.2.2. Odometer test. After swelling tests were completed, the samples of $10 \mathrm{~mm}$ height were loaded under prescribed stress paths $(50 \mathrm{kPa}-100 \mathrm{kPa}-200 \mathrm{kPa}$ $-400 \mathrm{kPa}-800 \mathrm{kPa}-1600 \mathrm{kPa})$. This part mainly focused on the compressive coefficient of samples, and did not take into account the effect of the secondary consolidation deformation during the loading process. So, after 12 hours, the samples were considered to be stable when the vertical deformation was less than $0.01 \mathrm{~mm}$ per hour. The vertical consolidation coefficient $C_{\mathrm{v}}$ under different vertical stress was measured by the time square root method:

$$
C_{\mathrm{v}}=\frac{0.848 \bar{h}^{2}}{t_{90}}
$$

Where $C_{\mathrm{v}}$ is the consolidation coefficient $\left(\mathrm{cm}^{2} / \mathrm{s}\right), \bar{h}$ is the maximum drainage distance $(\mathrm{cm}), t_{90}$ is the time required for consolidation to reach $90 \%$ (s).

According to Terzaghi's one-dimensional consolidation theory, the hydraulic conductivity of clay can be calculated (Sun et al. 2015):

$$
k=c_{\mathrm{v}} m_{\mathrm{v}} \gamma_{\mathrm{w}}
$$

Where $k$ is the hydraulic conductivity $(\mathrm{cm} / \mathrm{s}), m_{\mathrm{v}}$ is the volume compressibility $\left(\mathrm{m}^{2} / \mathrm{kN}\right), \gamma_{\mathrm{w}}$ is the gravity of water $\left(\mathrm{kN} / \mathrm{m}^{3}\right)$.

2.2.3. Scanning electron microscope test. In order to fully understand profoundly the macro performance changes of samples, the microstructure morphology of samples with the height of $10 \mathrm{~mm}$, the CMR of $0 \%$ and $12.5 \%$ was conducted by the scanning electron microscope. The apparatus used in the test was FEI Nova NanoSEM NPE produced by the USA.

The samples (the CMR of $0 \%$ and $12.5 \%$ ) were prepared after the swelling test $(400 \mathrm{kPa}$ vertical stress). Then some small elements with $2.5 \mathrm{~mm} * 2.5 \mathrm{~mm} * 5 \mathrm{~mm}$ that were cut out of the samples had to be dehydrated by liquid nitrogen. Finally, the microstructure morphology was conducted by the scanning electron microscope.

2.2.4. Direct shear test. In order to fully understand profoundly the macro performance changes of samples, the microstructure morphology of samples with the height of $10 \mathrm{~mm}$, the CMR of $0 \%$ and $12.5 \%$ was conducted by the scanning electron microscope. The apparatus used in the test was FEI Nova NanoSEM NPE produced by the USA.

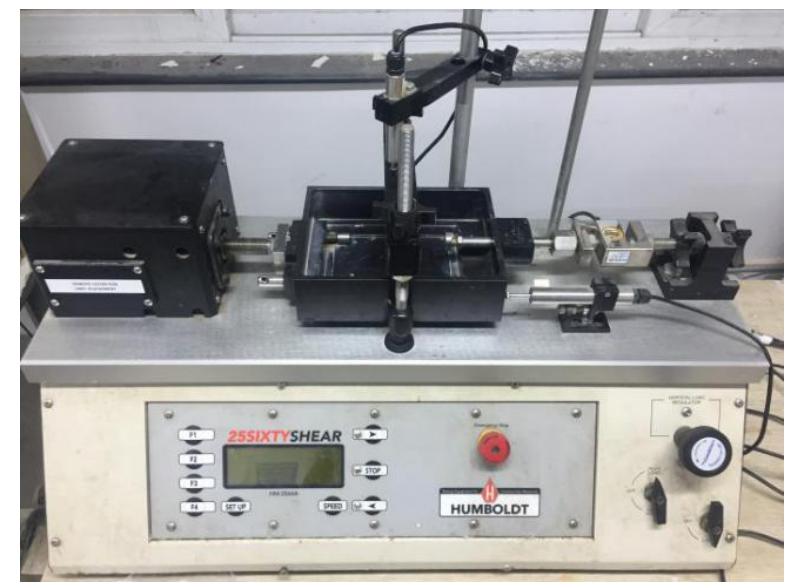

Figure 2. HUS-25sixty shear direct shear apparatus.

\section{Experimental results and analysis}

\subsection{Swelling test}

Figure $3 \mathrm{a}-3 \mathrm{c}$ presented the swelling strain vs. the time for three different vertical stresses $(200 \mathrm{kPa}, 400 \mathrm{kPa}$ and 
$800 \mathrm{kPa})$. As shown in Figure 3a-3c, it could be seen that while the vertical stress increased, the swelling strain of bentonite $/ \mathrm{CaCO}_{3}$ mixtures decreased. And under the same vertical stress, the swelling strain of samples decreases with the increase of the CMR under different vertical stresses. This phenomenon may be explained that the montmorillonite, which was the main swelling mineral in the bentonite, decreased as the content of $\mathrm{CaCO}_{3}$ powders increased under the same initial dry density. According to diffuse double layer theory [9], the repulsion between the bentonite particles decreased with the reduction of the content of montmorillonite. Especially under the low stress, the effect of CMR on the swelling strain was more obvious. At the same time, Figure $3 a-3 c$ also reflected the time required for the samples to stabilize. It could be found that the more the content of $\mathrm{CaCO}_{3}$ powders, the less the time required for the test. Under a vertical stress of $400 \mathrm{kPa}$, the test used with the pure bentonite took 14 days until the test was completed, and it took 10 days to complete the test with a mixed sample (the CMR was $12.5 \%$ ).

Sridharan et al. [34] reported three clear phases in swelling, viz., the initial swelling, the primary swelling, and the secondary swelling (Figure 4). The results (Figure 3) were consistent with that of Figure 4 and with the "S" shape.

Figure 5 presented some methods of tests for measuring the swelling pressure [35]. As shown in Figure 5, Gao et al. [35] introduced three methods for calculating the swelling pressure: the free swell and load test, the swell-under-load test and the constant volume test. The sample conducted by swell- under-load test was swelling in the case of one-dimensional, and then a vertical stress was applied to recover the initial void ratio, which was the highest value of the swelling pressure $\left(\sigma_{\mathrm{s} 1}\right)$. $\sigma_{\mathrm{s} 2}$, which was determined by the constant volume test, was generally considered to yield higher values than that of $\sigma_{\mathrm{s} 1}$ and $\sigma_{\mathrm{s} 3}$ was determined by the free swell and load test. But the value of $\sigma_{\mathrm{s} 3}$ was too large to be used as the swelling pressure of the bentonite due to the compression deformation of the unsaturated bentonite increased with increasing vertical stress before wetting, while $\sigma_{\mathrm{s} 2}$ was not unique under different constant vertical stresses. Thus, $\sigma_{\mathrm{s} 1}$ was more reasonable to use as the swelling pressure of the bentonite.

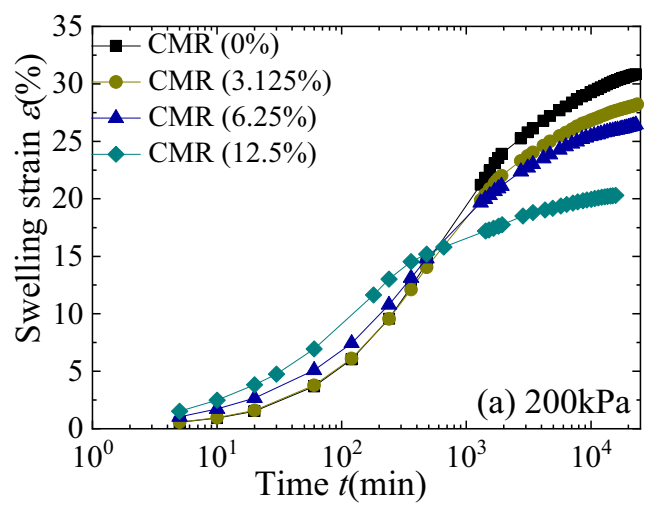

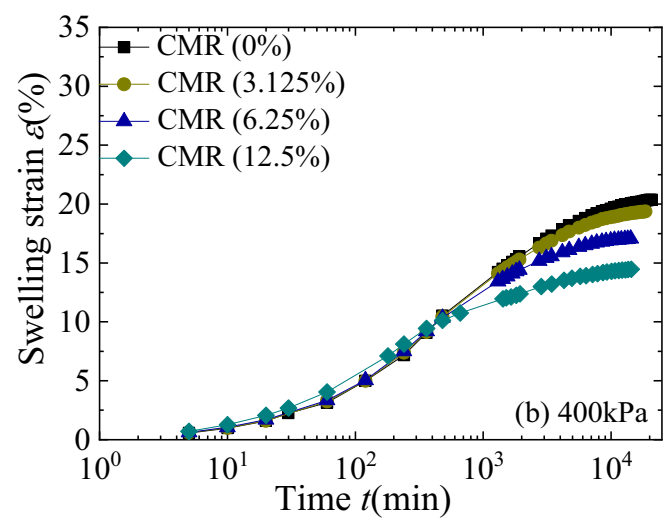

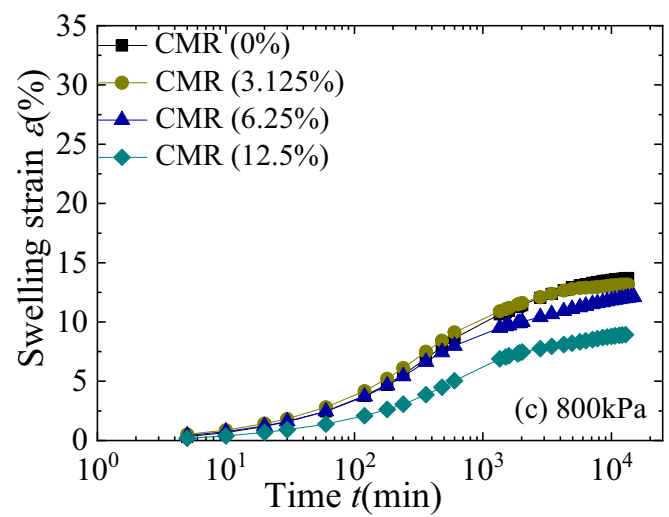

Figure 3. Swelling strain developed with time for bentonite/ $\mathrm{CaCO}_{3}$ mixtures under different vertical stress.

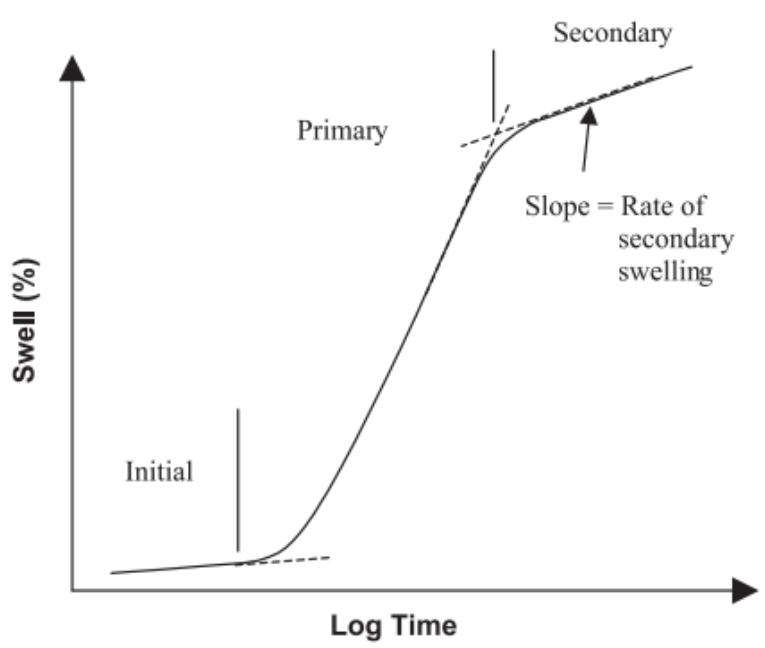

Figure 4. Scheme of initial, primary, and secondary swelling stages[34]. 


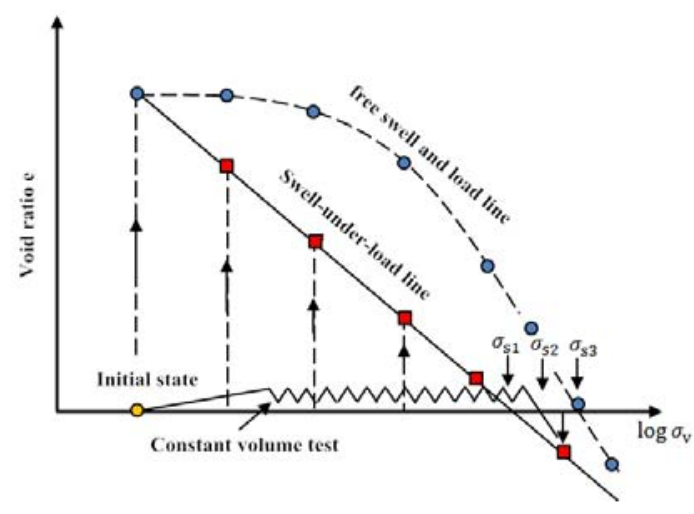

Figure 5. Methods of tests for measuring swelling pressure.

As shown in Figure 6, the swelling pressure of mixed samples decreased with the increase of CMR. According to the diffuse double layer theory, the repulsion between the clay particles could decrease with the increase of the content of $\mathrm{CaCO}_{3}$ powders due to the reduction of the content of montmorillonite per unit volume.

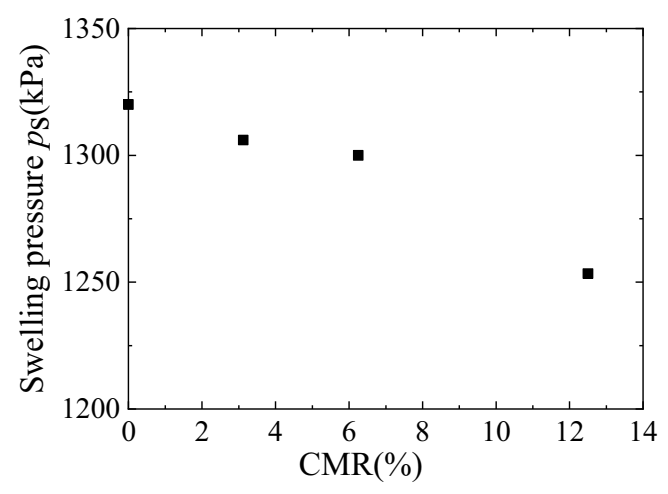

Figure 6. Swelling pressure for bentonite/ $\mathrm{CaCO}_{3}$ mixtures.

\subsection{Odometer test}

The compression curve of bentonite $/ \mathrm{CaCO}_{3}$ mixtures was shown in Figure 7. The compression curve presented a bilinear characteristic with an obvious inflection point. This phenomenon may be explained that with the increase of vertical stress, the transition of samples was generated from the elastic deformation of the original drainage to the plastic deformation of the structural failure. The compression becomes more difficult due to the further compact contact between particles.

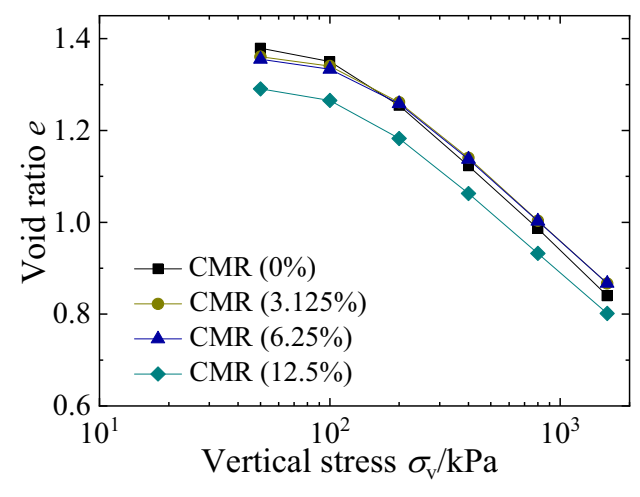

Figure 7. Void ratio vs. vertical pressure.

According to Figure 7, the compression index for bentonite $/ \mathrm{CaCO}_{3}$ mixtures was obtained in Figure 8. A line was obtained by linear fitting, and the fitting equation was Eq. (6). The compression index decreased slightly with the increase of $\mathrm{CaCO}_{3}$ content.

$$
C_{\mathrm{c}}=-0.273 C M R+0.467
$$

Where $C_{\mathrm{c}}$ is the compression index. According to Eq. (6), the compression indexes of the bentonite mixed with any CMR can be predicted $\left(\rho_{\mathrm{s}}=1.6 \mathrm{~g} / \mathrm{cm}^{3}\right)$.

It has been found that the determination of consolidation coefficient by the square root method was available to deduce the hydraulic conductivity of clay sample [36]. In the paper of Sun et al. [36], this method was used to remove the anomalous points due to the interaction of the volume compression coefficient and the consolidation coefficient. It can be seen from Figure 9 that the hydraulic conductivity of samples decreased with the increase of the content of $\mathrm{CaCO}_{3}$ powders, as a consequence of the quite small size of the $\mathrm{CaCO}_{3}$ crystal particles which existed and blocked the pores.

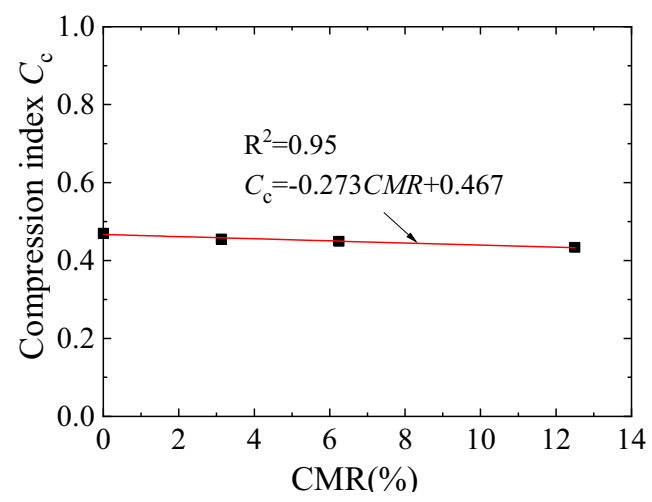

Figure 8. Compression index for bentonite $/ \mathrm{CaCO}_{3}$ mixtures. 


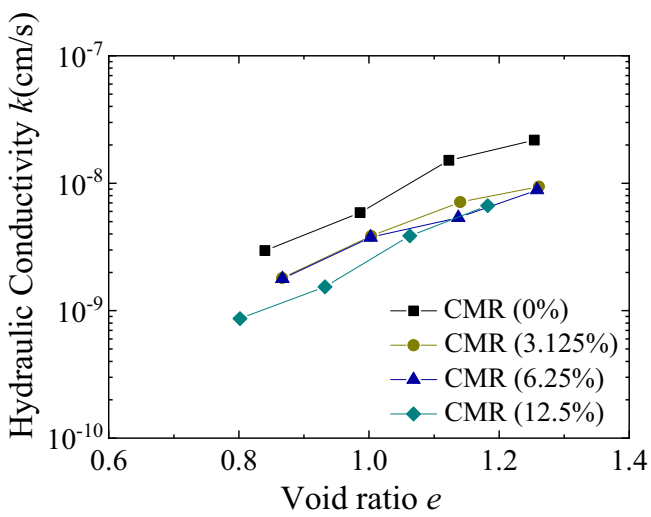

Figure 9. Hydraulic conductivity vs. void ratio.

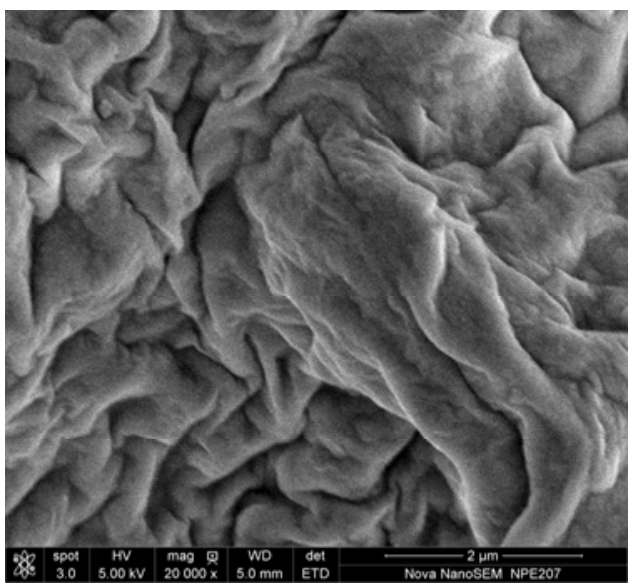

\subsection{Microstructure}

Figure 10 presented the images of bentonite $/ \mathrm{CaCO}_{3}$ mixtures which were obtained at a magnification of 20000 times under the scanning electron microscope. It could be clearly seen from Figure 10 that the surface structure of samples mixed with $\mathrm{CaCO}_{3}$ crystals was denser because the presence of $\mathrm{CaCO}_{3}$ crystals filled the pores of the clay sample to make the surface smoother and the structure denser. So, it resulted in the decrease of the hydraulic conductivity, which was consistent with the above macro-trait analysis.

Figure 10. SEM photomicrographs of bentonite $/ \mathrm{CaCO}_{3}$ mixtures under $400 \mathrm{kPa}$ vertical stress (20000*): (a) $\mathrm{CMR}-0 \%$; and (b) CMR-12.5\%.

\subsection{Direct shear test}

Figure 11, 12 and 13 presented displacement vs. shear stress under $200 \mathrm{kPa}$ vertical stress for unsaturated bentonite $/ \mathrm{CaCO}_{3}$ mixtures, shear strength vs. CMR for unsaturated and saturated samples and shear strength vs. vertical stress for unsaturated and saturated samples, respectively. As shown in Figure 11, the unsaturated mixed samples showed the behavior of strain softening under $200 \mathrm{kPa}$ vertical stress. In addition, the saturated samples and unsaturated samples under other vertical stresses showed the same strain softening behavior. The peak point of the shear stress-displacement curve was defined as the shear strength of mixed samples. As shown in Figure 12(a), the shear strength of unsaturated samples increased first and then decreased as the CMR increased, and the peak point occurred when the CMR was $3.125 \%$. From Figure 12(b), it could be seen that the shear strength of saturated samples increased at first and then decreased under the low stress, but the shear strength decreased at first and then increased under the high stress, as consequences of the interaction of cohesion and internal friction angle.

According to the relationship between the shear strength and vertical stress (Figure 13), the parameters of mixed samples were shown in Table 3. For unsaturated samples, the two parameters firstly increased and then decreased with the increase of CMR. When the CMR was sufficiently small, the particles of the bentonite were bound tightly due to the cementation of $\mathrm{CaCO}_{3}$ crystals, resulting in the increase of cohesion. Meanwhile, a small amount of the $\mathrm{CaCO}_{3}$ crystals bonded with near the bentonite particles could increase the frictional resistance. However, with the increase of $\mathrm{CaCO}_{3}$ content, the relative content of the bentonite particles decreased so that the cohesion decreased due to the reduction of total van der Waals force. The higher the content of $\mathrm{CaCO}_{3}$ crystals, the smaller the friction and internal friction angle of mixed samples. For saturated mixed samples, the cohesion of mixed samples showed the trend of decreasing firstly and then increasing with the CMR. 


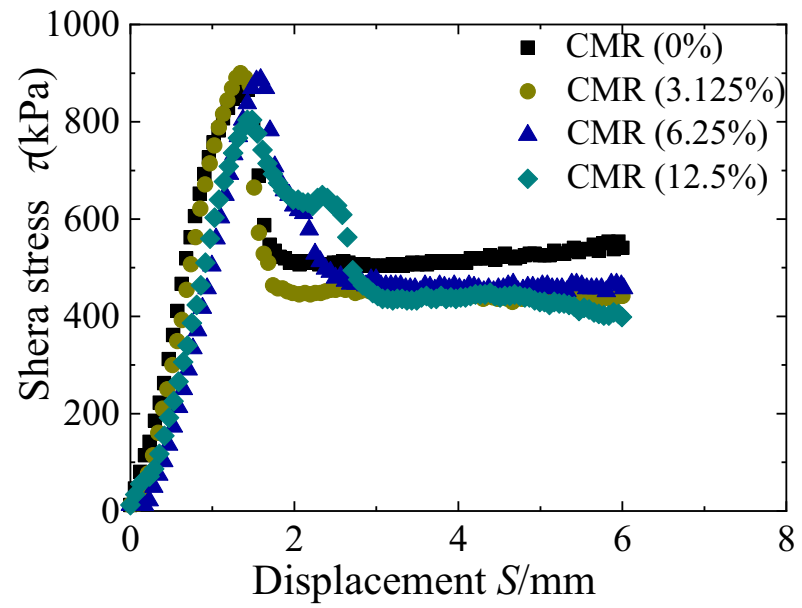

Figure 11. Shear stress vs. displacement for unsaturated bentonite/ $\mathrm{CaCO}_{3}$ mixtures under vertical stress $200 \mathrm{kPa}$.
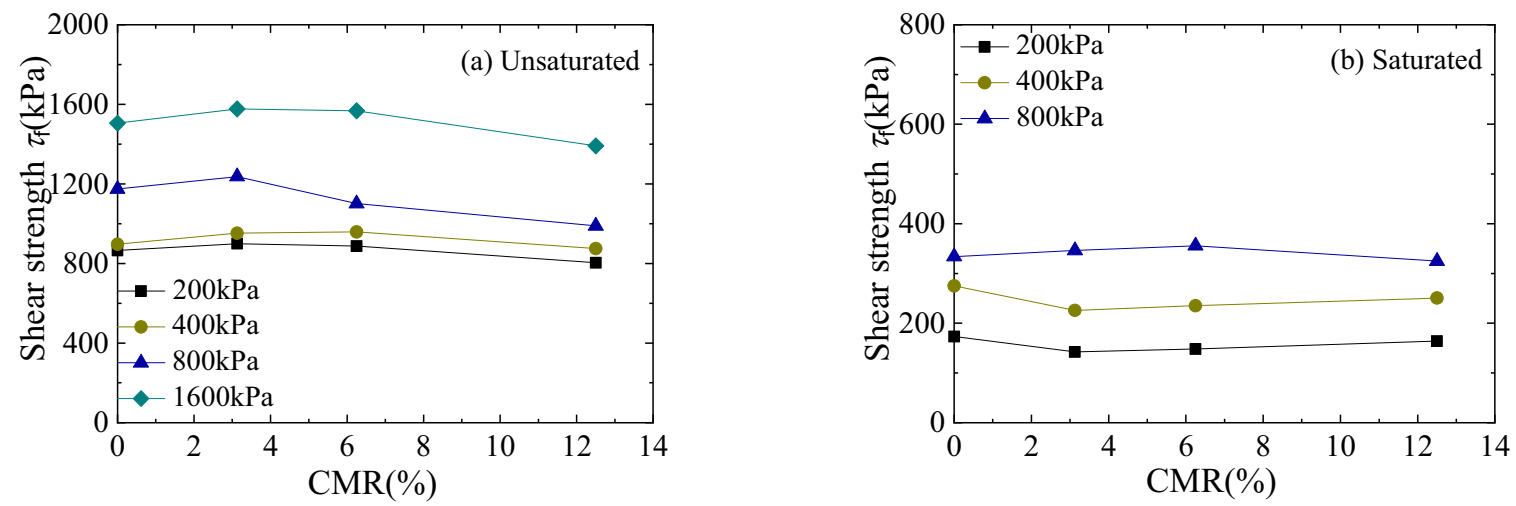

Figure 12. Shear strength vs. CMR.
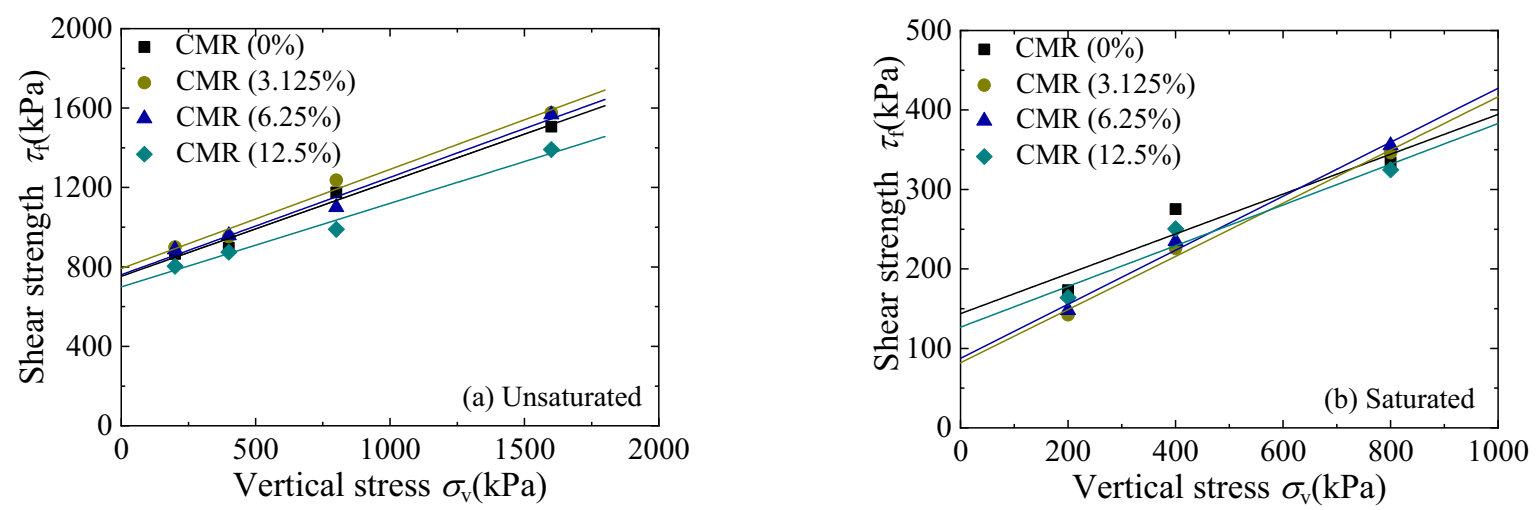

Figure 13. Shear strength vs. vertical stress.

As shown in Table 3, the cohesion between unsaturated and saturated samples was of significant difference because the cohesion of unsaturated samples was not only derived from Van der Waals forces, the gravitational or the repulsive force of the electric double layer, the cementation caused by the solute precipitation, etc., but also from the capillary effect caused by the unique surface tension of unsaturated clay. 
Table 3. Parameter for the bentonite/CaCO3 mixtures

\begin{tabular}{cccc}
\hline Sample & CMR $(\%)$ & Cohesion $(\mathrm{kPa})$ & Internal friction angle $\left(^{\circ}\right)$ \\
\hline Unsaturated & 0 & 752.9 & 25.50 \\
& 3.125 & 792.1 & 26.52 \\
& 6.25 & 760.7 & 26.12 \\
Saturated & 12.5 & 699.4 & 22.81 \\
& 0 & 143.8 & 14.07 \\
& 3.125 & 81.9 & 18.50 \\
& 6.25 & 87.6 & 18.76 \\
& 12.5 & 126.8 & 14.37 \\
\hline
\end{tabular}

S462-S471.

\section{Conclusion}

In this paper, some experiments were conducted to study the effects of different $\mathrm{CaCO}_{3}$ contents on the swelling, compression, permeability and shear strength of the bentonite. The results were as follows:

The swelling properties of bentonite $/ \mathrm{CaCO}_{3}$ mixtures varied with the CMR. With the increase of the $\mathrm{CaCO}_{3}$ content, the swelling strain and swelling pressure of bentonite $/ \mathrm{CaCO}_{3}$ mixtures decreased. While the vertical stress increased, the swelling strain of bentonite $/ \mathrm{CaCO}_{3}$ mixtures decreased.

While the content of $\mathrm{CaCO}_{3}$ powders was less, the $\mathrm{CaCO}_{3}$ powders had little effects on the compressive properties of bentonite $/ \mathrm{CaCO}_{3}$ mixtures. The existence of $\mathrm{CaCO}_{3}$ crystals would lead to the change of the microstructure. The $\mathrm{CaCO}_{3}$ crystals blocked the pores of bentonite to narrow the permeate channel of the liquid medium. While the content of $\mathrm{CaCO}_{3}$ powders increased, the permeability of mixtures decreased.

While the increase of CMR, the cohesion of unsaturated samples first increased and then decreased, but saturated samples presented the opposite character. As for the internal friction angle of saturated and unsaturated samples, it first increased and then decreased.

\section{Acknowledgement}

The authors are grateful to the National Natural Science Foundation of China (projects No. 41372279, 41572284).

\section{References}

1. Villar, M.V., Lloret, A. (2008) Influence of dry density and water content on the swelling of a compacted bentonite. Applied Clay Science, 39(1-2): 38-49.

2. Komine, H., Watanabe, Y. (2010) The past, present and future of the geo-environment in Japan. Soils and Foundations, 50(6): 977-982.

3. Cui, Y.J., Tang, A.M., Loiseau, C., Delage, P. (2008) Determining the unsaturated hydraulic conductivity of a compacted sand-bentonite mixture under constant-volume and free-swell conditions. Physics and Chemistry of the Earth, Parts $\mathrm{A} / \mathrm{B} / \mathrm{C}, 33$ :
4. Cui, Y.J., Tang, A.M., Qian, L.X., Ye, W.M., Chen, B. (2011) Thermal-mechanical behavior of compacted GMZ Bentonite. Soils and foundations, 51(6): 1065-1074.

5. Ye, W.M., Wan, M., Chen, B., Chen, Y.G., Cui, Y.J., Wang, J. (2012) Temperature effects on the unsaturated permeability of the densely compacted GMZ01 bentonite under confined conditions. Engineering Geology, 126: 1-7.

6. Sun, D.A. (2009) Hydro-mechanical behaviours of unsaturated soils and their elastoplastic modeling. Rock and Soil Mechanics, 30(11): 3217-3231.

7. Sun, D. A. (2009) Effect of saturation degree on mechanical behaviours of unsaturated soils. Rock and soil mechanics, 30(S2): 13-16.

8. Komine, H., Yasuhara, K., Murakami, S. (2009) Swelling characteristics of bentonites in artificial seawater. Canadian Geotechnical Journal, 46(2): 177-189.

9. Ye, W.M., Cui, Y.J., Qian, L.X., Qian, L.X., Chen, B. (2009) An experimental study of the water transfer through confined compacted GMZ bentonite. Engineering Geology, 108(3-4): 169-176.

10. Ye, W.M., Lai, X.L., Liu, Y., Chen, Y.G., Cui, Y.J. (2013) Ageing effects on swelling behaviour of compacted GMZ01 bentonite. Nuclear Engineering and Design, 265: 262-268.

11. Komine, H., Ogata, N. (2004) Predicting swelling characteristics of bentonites. Journal of Geotechnical and Geoenvironmental engineering, 130(8):818-829.

12. Chen, W.C., Huang, W.H. (2013) Effect of groundwater chemistry on the swelling behavior of a Ca-bentonite for deep geological repository. Physics and Chemistry of the Earth, Parts A/B/C, 65: 42-49.

13. Ye, W.M., Wan, M., Chen, B., Chen, Y.G., Cui, Y.J., Wang, J. (2014) An unsaturated hydraulic conductivity model for compacted GMZ01 bentonite with consideration of temperature. Environmental earth sciences, 71(4): 1937-1944.

14. Gueddouda, M.K., Lamara, M., Abou-Bekr N., Taibi S. (2010) Hydraulic behaviour of dune sand-bentonite mixtures under confining stress. Geomechanics and Engineering, 2(3): 213-227.

15. Tang, A.M., Cui, Y.J., Barnel, N. (2007) A new isotropic cell for studying the thermo-mechanical 
behavior of unsaturated expansive clays. Geotechnical Testing Journal, 30(5): 341-348.

16. Tang, A.M., Cui, Y.J., Barnel, N. (2008) Thermo-mechanical behaviour of compacted expansive swelling clay. Geotechnique, 58(1): 45-54.

17. Tang, A.M., Cui, Y.J. (2009) Modelling the thermo-mechanical behaviour of compacted expansive clays. Geotechnique, 59(3): 185-195.

18. Ye, W.M., Wan, M., Chen, B., Chen, Y.G., Cui, Y.J., Wang, J. (2013) Temperature effects on the swelling pressure and saturated hydraulic conductivity of the compacted GMZ01 bentonite. Environmental earth sciences, 68(1): 281-288.

19. Ye, W.M., Wan, M., Chen, B., Chen, Y.G., Cui, Y.J., Wang, J. (2014) Effects of $\mathrm{pH}$ and temperature on the swelling pressure and hydraulic conductivity of compacted GMZ01 bentonite. Applied Clay Science, 101: 192-198.

20. Sun, D.A., Zhang, J. and Song, G. (2013) Experimental study of soil-water characteristic curve of chlorine saline soil. Rock and Soil Mechanics, 4: 008 .

21. Liu, Y.M., Wang, J., Cao, S.F., Ma, L.K., Xie, J.L., Zhao, X.G., Chen, L. (2013) A large-scale THMC experiment of buffer material for geological disposal of high level radioactive waste in China. Rock Soil Mech, 34(10): 2756-2789.

22. Qin, A.F., Fu, X.L., Sun, D.A., Ruan, K.L., Li, T.Y. (2019) Influences of chemo-mechanical coupling on the volume change behaviour of bentonite. Chinese Journal of Rock Mechanics and Engineering, 38(S2):3775-3782.

23. Ye, W.M., Zhang, F., Chen, B., Chen, Y.G., Wang, Q., Cui, Y.J. (2014c) Effects of salt solutions on the hydro-mechanical behavior of compacted GMZ01 Bentonite. Environmental earth sciences, 72(7): 2621-2630.

24. Olivella, S., Carrera, J., Gens, A., Alonso, E.E. (1994) Nonisothermal multiphase flow of brine and gas through saline media. Transport in porous media, 15(3): 271-293.

25. Olivella, S., Gens, A. (2000) Vapour transport in low permeability unsaturated soils with capillary effects. Transport in Porous Media, 40(2): 219-241.

26. Gens, A., Garcia-Molina, A.J., Olivella, S., Alonso, E.E., Huertas, F. (1998) Analysis of a full scale in situ test simulating repository conditions. International Journal for Numerical and Analytical Methods in Geomechanics, 22(7): 515-548.

27. Gens, A., Olivella, S. (2001) Clay barriers in radioactive waste disposal. Revue française de génie civil, 5(6): 845-856.

28. Kim, J.S., Kwon, S.K., Sanchez, M., Cho, G.C. (2011) Geological storage of high level nuclear waste. KSCE Journal of Civil Engineering, 15(4): 721-737.

29. Harrington, J.F., Milodowski, A.E., Graham, C.C.,
Rushton, J.C., Cuss, R.J. (2012) Evidence for gas-induced pathways in clay using a nanoparticle injection technique. Mineralogical Magazine, 76(8): 3327-3336.

30. Cui, Y.J. (2017) On the hydro-mechanical behaviour of MX80 bentonite-based materials. Journal of Rock Mechanics and Geotechnical Engineering, 9(3): 183-192.

31. Guo, Y.H., Wang, J., Xiao, F., Wang, Z.M., Liu, S.F., Rui, S., Zong, Z.H., Li Y.W., Wang H.L. (2010) Groundwater formation in Beishan (Gansu) preselected area of high-level radioactive waste disposal repository. Geological Journal of China Universities, 16(1): 13-18.

32. Guo, Y.H., Li N.N., Zhou Z.C., Dong J.N., Ji R.L., Liu S.F. (2014) Groundwater chemical characteristics in yamansu and tianhu section for high level radioactive waste disposal repository. Nuclear and Radiochemistry, 36: 78-84.

33. Sasaki, T., Kuwano, R. (2016) Undrained cyclic triaxial testing on sand with non-plastic fines content cemented with microbially induced $\mathrm{CaCO}_{3}$. Soils and Foundations, 3(56): 485-495.

34. Sridharan, A., Gurtug, Y. (2004) Swelling behaviour of compacted fine-grained soils. Engineering Geology, 72(1): 9-18.

35. Gao, Y., Sun, D.A., Wu, Y.J. (2018) Volume change behaviour of unsaturated compacted weakly expansive soils. Bulletin of Engineering Geology and the Environment, 77: 837-848

36. Sun, W.J., Liu, S.Q., Sun, D.A., Fang, L. (2015) Permeability of saturated Gaomiaozi Bentonite. Chinese Journal of Underground Space and Engineering, 11(1): 115-119. 